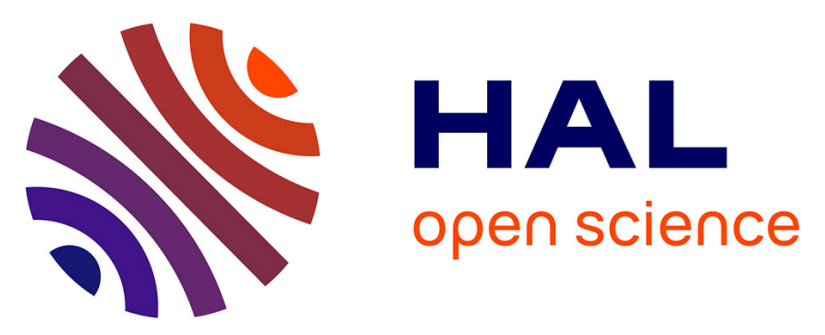

\title{
Physiological traits of Penicillium glabrum strain LCP 08.5568, a filamentous fungus isolated from bottled aromatised mineral water
}

Laurent Nevarez, Valérie Vasseur, A. Le Madec, M. A. Le Bras, Louis

Coroller, Ivan Leguérinel, Georges Barbier

\section{To cite this version:}

Laurent Nevarez, Valérie Vasseur, A. Le Madec, M. A. Le Bras, Louis Coroller, et al.. Physiological traits of Penicillium glabrum strain LCP 08.5568, a filamentous fungus isolated from bottled aromatised mineral water. International Journal of Food Microbiology, 2009, 130 (3), pp.166-171. 10.1016/j.ijfoodmicro.2009.01.013 . hal-00551244

\section{HAL Id: hal-00551244 \\ https://hal.univ-brest.fr/hal-00551244}

Submitted on 3 Jan 2011

HAL is a multi-disciplinary open access archive for the deposit and dissemination of scientific research documents, whether they are published or not. The documents may come from teaching and research institutions in France or abroad, or from public or private research centers.
L'archive ouverte pluridisciplinaire HAL, est destinée au dépôt et à la diffusion de documents scientifiques de niveau recherche, publiés ou non, émanant des établissements d'enseignement et de recherche français ou étrangers, des laboratoires publics ou privés. 


\section{Physiological traits of Penicillium glabrum strain LCP 08.5568,}

\section{2 a filamentous fungus isolated from bottled aromatised mineral}

3 water

L. Nevarez *, V.Vasseur, A. Le Madec, M.A. Le Bras, L. Coroller, I. Leguérinel, G. Barbier

-Université Européenne de Bretagne, France

-Université de Brest, EA3882 Laboratoire Universitaire de Biodiversité et Ecologie Microbienne, IFR148 ScInBioS, ESMISAB, Technopôle de Brest Iroise, 29280 Plouzané, France.

*Corresponding author. Fax : +33298056101 


\section{Abstract}

Penicillium glabrum is an ubiquitous fungus distributed world wide. This fungus is a frequent contaminant in the food manufacturing industry. Environmental factors such as temperature, water activity and $\mathrm{pH}$ have a great influence on fungal development. In this study, a strain of $P$. glabrum referenced to as LCP 08.5568 , has been isolated from a bottle of aromatised mineral water. The effects of temperature, $a_{\mathrm{w}}$ and $\mathrm{pH}$ on radial growth rate were assessed on Czapeck Yeast Agar (CYA) medium. Models derived from the cardinal model with inflection (Rosso et al., 1993 An unexpected correlation between cardinal temperatures of microbial growth highlighted by a new model. J Theor. Bio. 162, 447-463) were used to fit the experimental data and determine for each factor, the cardinal parameters (minimum, optimum and maximum). Precise characterisation of the growth conditions for such a fungal contaminant, has an evident interest to understand and to prevent spoilage of food products.

Keywords: Penicillium glabrum, predictive mycology, food spoilage, fungal growth, temperature, water activity, $\mathrm{pH}$, 


\section{Introduction}

Filamentous fungi are widely distributed in the environment and responsible for numerous spoilage of food products (Pitt and Hocking, 1997; Samson et al., 2004). In addition to the economic losses associated to their visual appearance, another concern is the possibility of offflavours and mycotoxins production. The most widespread and frequent mould spoilages of food products are caused by several genera such as Aspergillus, Fusarium or Penicillium. Among this last genus, Penicillium glabrum is an ubiquitous and cosmopolitan fungus, frequently encountered in food manufacturing industry, due to its wide presence and its important conidiation (Pitt and Hocking, 1997). This filamentous fungus has been previously isolated in a large variety of products as cheese (Northolt et al., 1980; Hocking and Faedo, 1992), maize (Mislivec and Tuite, 1970), commercially marketed chestnuts (Overy et al., 2003), rice (Kurata et al., 1968), jam (Udagawa et al., 1977) and bottled water (Cabral and Fernandez Pinto, 2002; Ancasi et al., 2006). To our knowledge, this fungal contaminant does not seem to produce any known mycotoxin that could threat the food safety and the consumer heath (Pitt and Hocking, 1997). Nevertheless, no precise affirmation can be formulated due to inherent differences which could be observed among several strains of the same species. Despite its large implication in food contamination, to our knowledge, very few studies have been conducted to characterise precisely growth conditions of this species.

Growth of filamentous fungi is influenced by a variety of environmental or intrinsic factors. Temperature and water activity $\left(a_{\mathrm{w}}\right)$, for example, are recognised as the most important ones that determine the ability of moulds to grow (Dantigny et al., 2005). Other factors such as the composition and intrinsic factors of the product, especially $\mathrm{pH}$, potentially influence the fungal development.

In order to analyse the physiological traits of a strain of $P$. glabrum isolated from a polyethylene terephthalate (PET) bottled aromatised mineral water, the present study aims at determining the cardinal values of this strain for temperature, $a_{w}$ and $\mathrm{pH}$. After investigating in solid 
medium, its mycelial growth response towards different factors: temperature, $a_{\mathrm{w}}$ and $\mathrm{pH}$, the development of this strain was studied by using a predictive mycology approach.

For over 20 years, predictive microbiology was focused mainly on food-pathogenic bacteria (Buchanan, 1993) and despite a similar interest, modelling filamentous fungal growth has not received the same level of attention. Actually, quantification of fungal growth is more complicated because, whereas bacteria reproduce by fission and grow homogeneously through a liquid medium, filamentous fungal growth implicated the development of tree-dimensional ramified hyphae with apical growth (Gibson et al., 1994; Gibson and Hocking, 1997). Taking account of these difficulties, the predictive mycology has been developed in several studies (Dantigny et al., 2005) by adapting different models used for bacterial investigations (Ratkowsky et al., 1983; Davey, 1989; Rosso et al., 1993; Baranyi et al., 1993; Miles et al., 1997). It appears that cardinal models with inflection (CMI) are suitable for modelling the effect of environmental factors on fungal growth (Rosso and Robinson, 2001). This kind of model originally developed for bacteria (Rosso et al., 1993; Rosso et al., 1995) has been successfully used to the effect of $\mathrm{a}_{\mathrm{w}}$ on growth of several filamentous fungi such as P. chrysogenum or Aspergillus flavus (Sautour et al., 2001a).

In the present study, CMI were used to model the effects of temperature, $a_{\mathrm{w}}$ and $\mathrm{pH}$ on the radial growth rate of $P$. glabrum. This method allows the estimation of the cardinal values of this filamentous fungus for each tested factor. These results define the eco-physiological requirements of this fungal contaminant and has an evident interest to understand its contamination abilities in food manufacturing industry. 


\subsection{Isolation and identification of the mould}

112

113

114

115

Visible pellets were observed in a sealed PET bottle of aromatised mineral water. Three samples of $100 \mathrm{~mL}$ were shaken and filtered through sterile membrane porosity $0.45 \mu \mathrm{m}$ (Millipore, Guyancourt, France). Visible hyphae were then transferred on Potato Dextrose Agar medium (PDA, Difco Laboratories, Detroit, MI, USA) and incubated for 7 days at $25^{\circ} \mathrm{C}$. A loopfull taken from a visible colony was examined under a microscope for morphological visualisation. Microscopic evaluation of the filamentous fungi isolated, indicated morphology similar to the description given by Pitt and Hocking for the genus Penicillium (phialides bearing chains of conidies) (Pitt and Hocking, 1997; Samson et al., 2004). The phialides were attached to the stipe directly, so the species produces monoverticillate penicilli and was classified in the subgenus Aspergilloïdes. Identification of the mould was further completed with inoculation of different media incubated at different temperatures following the reference method (Pitt, 1988). Observations were made on the morphology and diameters of the colonies and this filamentous fungus was characterised as Penicillium glabrum (Wehmer) Westling. This strain was registered as LMSA 1.01.421 in "'Souchothèque de Bretagne"' (University of Brest, France / www.ifremer.fr/souchotheque) and LCP 08.5568 in the fungal collection of Laboratory of cryptogamy, Museun Nationnal d'Histoire Naturelle (Paris, France / www.mnhn.fr).

(1)

\subsection{Media preparation and culture conditions}

The effect of each factor tested experimentally on the growth of this strain of P. glabrum, was studied in solid cultures using inoculum consisted in conidia harvested from 7 days-old grown in PDA medium at $25^{\circ} \mathrm{C}, 0.99 a_{\mathrm{w}}$ and $\mathrm{pH}$ 5.5. Conidia were suspended in $1 \mathrm{~mL}$ of sterile water with 
0,01\% Tween 80 (Sigma-Aldrich, Saint Louis, MO, USA). One drop of inoculum containing $10^{4}$ spores $/ \mathrm{ml}$, was applied with thin pipette, on two points equidistant from the center and the edge of Petri dish that contained the Czapeck Yeast Agar medium (CYA).

Temperature investigations: standard CYA medium was used and contained $3 \%$ sucrose, 0.5 $\%$ yeast extract, $0.1 \% \mathrm{~K}_{2} \mathrm{HPO}_{4}, 1.5 \%$ agar and $1 \%$ Czapek concentrate $\left(5 \% \mathrm{KCl}, 30 \% \mathrm{NaNO}_{3}, 5\right.$ $\% \mathrm{MgSO}_{4}, 7 \mathrm{H}_{2} \mathrm{O}, 0.01 \% \mathrm{FeSO}_{4} .7 \mathrm{H}_{2} \mathrm{O}$ and $\left.0.01 \% \mathrm{CuSO}_{4} .7 \mathrm{H}_{2} \mathrm{O}\right) . \mathrm{pH}$ and $\mathrm{a}_{\mathrm{w}}$ were respectively measured at 6.8 and 0.99. After inoculation of 12 replicates (6 plates), for each condition tested, media were then incubated for 7 days at temperatures in the ranges $5-45{ }^{\circ} \mathrm{C}$.

Water activity investigations: CYA media were adjusted to various $a_{\mathrm{w}}$ from 0.79 to 0.99 by substituting a part of water by glycerol (w/w) according to the relation of Langmuir (Lerici et al., 1996): $\mathrm{M}($ water $(\mathrm{g}) /$ glycerol $(\mathrm{g}))=0.236 a_{\mathrm{w}} /\left(1-0.99 a_{\mathrm{w}}\right)$. Inoculations were realised, as described previously except that inoculum was only applied in one point per plate. Triplicate plates were inoculated for most $a_{\mathrm{w}}$ tested $(0.79,0.81,0.83,0.85,0.87,0.89,0.91,0.92,0.93,0.94)$ and for highest values $(0.95,0.96,0.97,0.98$ and 0.99$), 8$ replicated plates were realised. The different media were incubated at $25{ }^{\circ} \mathrm{C}$ for 7 days. During the experiments, $a_{\mathrm{w}}$ of each medium was stabilised by placing Petri dishes in 1,5 1 closed boxes with a glycerol-water solution of the same $a_{\mathrm{w}}$ as the medium (Sautour et al., 2001b). Stability of the different media was also controlled by assessing $a_{\mathrm{w}}$ with FA-st/1 (CBX Scientific Instruments, Romans, France).

pH investigations: cultures of P. glabrum strain LCP 08.5568 were realised in different CYA media with $\mathrm{pH}$ adjusted to each experimental condition. Precise volumes of sterile $\mathrm{H}_{3} \mathrm{PO}_{4} 5 \mathrm{M}$, $\mathrm{H}_{3} \mathrm{PO}_{4} 2 \mathrm{M}$ and $\mathrm{NaOH} 1 \mathrm{M}$, were added respectively for $\mathrm{pH}$ 0.5-2.0, $\mathrm{pH} 3.0-7.0$ and for $\mathrm{pH}$ 8.0-11.0 (Table 1). The adjusted media from $\mathrm{pH} 0.5$ to 11.0 were inoculated as previously described using 8 replicates ( 4 plates) for each conditions tested. The different media were then incubated at $25{ }^{\circ} \mathrm{C}$ for 7 days. The $\mathrm{pH}$ values of each medium used, was also measured after 7 days of culture in order to confirm their stability. 


\subsection{Growth rate calculation}

165

Each factor was studied individually at 5 levels of temperature, 12 levels of $a_{w}$ and 11 levels

of $\mathrm{pH}$ containing for each level 12,3 or 8 and 8 replicates respectively. The radius of the colony

(mm) was measured in two directions at right angle and the mean was plotted against time (d). The radial growth rate $\mu\left(\mathrm{mm} \mathrm{d}^{-1}\right)$ was defined as the slope of the straight line.

170 9

\subsection{Model equations}

The relationship between the growth rate $(\mu)$ and the 3 environmental factors tested (temperature, $\mathrm{a}_{\mathrm{w}}$ and $\mathrm{pH}$ ) were assessed using the equations described below. The equations are based on the cardinal model with inflection (CMI) approach. For temperature the CMI originally developed by Rosso et al. (1993) was used

$$
\mu(T)=\frac{\mu_{o p t}\left(T-T_{\max }\right)\left(T-T_{\min }\right)^{2}}{\left(T_{o p t}-T_{\min }\right)\left[\left(T_{o p t}-T_{\min }\right)\left(T-T_{o p t}\right)-\left(T_{o p t}-T_{\max }\right)\left(T_{o p t}+T_{\min }-2 T\right)\right]}
$$

The CMI modified by Sautour et al. (2001a) was used for $a_{\mathrm{w}}$

$$
\mu\left(a_{w}\right)=\frac{\mu_{o p t}\left(a_{w}-1\right)\left(a_{w}-a_{w \min }\right)^{2}}{\left(a_{w_{\text {opt }}}-a_{w \min }\right)\left[\left(a_{w_{\text {opt }}}-a_{w \min }\right)\left(a_{w}-a_{w_{\text {opt }}}\right)-\left(a_{w \text { opt }}-1\right)\left(a_{w_{\text {opt }}}+a_{w \min }-2 a_{w}\right)\right]}
$$

For $\mathrm{pH}$ the CMI described by Rosso et al. (1995) was used

$$
\mu(p H)=\frac{\mu_{o p t}\left(p H-p H_{\text {min }}\right)\left(p H-p H_{\text {max }}\right)}{\left(p H-p H_{\text {min }}\right)\left(p H-p H_{\text {max }}\right)-\left(p H-p H_{o p t}\right)^{2}}
$$




\subsection{Model fitting and determination of cardinal conditions}

193

194

195

196

197

198

199

200

Before fitting, a square-root transformation was performed to homogenise the variance of the experimental growth rate (Dantigny and Bensoussan, 2008). Cardinal values were determined by iterative calculation based on minimising the sum of squares of the residual values (SSR) with NLINFIT function of MATLAB R2008A (The Math-works). $95 \%$ confidence intervals were obtained by using traditional methods based on a linear approximation with NLPARCI function in MATLAB. For each factor modeled the Root Mean Square Error (RMSE) was calculated in order to measure the goodness of fit of each model. According to Ratkowsky (2004), this criterion should be preferred to the regression coefficient $r^{2}$ for non-linear models.

\section{Results and discussion}

\subsection{Effect of temperature}

The experimental growth results obtained in different conditions of temperature after 7 days of culture in CYA medium, were used to model the growth of this strain according to equation 1 of the CMI (Fig. 1). The minimal, optimal and maximal temperatures were estimated to 6.6, 24.3 and $33.8^{\circ} \mathrm{C}$ respectively (Table 2). A good quality of fit was obtained as suggested by the low RMSE value of 0.077 .

The optimal temperature around $24{ }^{\circ} \mathrm{C}$ for this strain of $P$. glabrum, is in accordance with literature data for this species that describes also an optimum around $25^{\circ} \mathrm{C}$ (Pitt and Hocking, 1997; Sinigaglia et al., 1998). Similar results were also reported in studies related to $P$. chrysogenum (Gonzalez et al., 1988), P. expansum (Lahlali et al., 2005), P. digitatum and P. italicum (Plaza et al., 2003). Meanwhile, optimal temperature varied slightly from $20{ }^{\circ} \mathrm{C}$ for P. polonicum (Nunez et al., 2000) to $30{ }^{\circ} \mathrm{C}$ for $P$. citrinum (Gonzalez et al., 1988; Montani et al., 1988). The range of 
temperatures from 20 to $30{ }^{\circ} \mathrm{C}$ is frequently encountered in food manufacturing industries and may be also reached in non-refrigerated storage of some products as bottles of aromatised mineral water. The maximal temperature condition for this filamentous fungus was close to $34{ }^{\circ} \mathrm{C}$ which is in accordance with some data reporting the absence of growth above $37^{\circ} \mathrm{C}$ (Pitt and Hocking, 1997) but differs from others reporting a fungal growth up to $40{ }^{\circ} \mathrm{C}$ (Sinigaglia et al., 1998). Results obtained for this strain of $P$. glabrum also showed the minimal temperature condition of $7^{\circ} \mathrm{C}$ which may differ from literature data, reporting a slight development of microcolonies up to $4 \mathrm{~mm}$ after several days at $5.0^{\circ} \mathrm{C}$ (Pitt, 1988).

\subsection{Effect of water activity}

As reported previously (Sautour et al., 2001a), a gradual increase in the radial growth rate was exhibited at sub optimal water activities. In contrast a sharp decrease in the growth rate was observed was noticed between the optimum and 1 (Fig 2). The minimal and the optimal $a_{\mathrm{w}}$ were estimated to 0.820 and 0.983 respectively (Table 2). A good quality of fit was obtained as suggested by the low RMSE value of 0.078 .

The minimal $a_{\mathrm{w}}$ for this stain 0.82 was less than the minimal value $0.88 a_{\mathrm{w}}$ reported previously in another study for this species (Sinigaglia et al., 1998). Filamentous fungi are among the organisms capable of growing below 0.90 (Pitt and Hocking, 1997) and most Penicillium species presented a minimal $a_{\mathrm{w}}$ between 0.82 and 0.86 (Northolt et al., 1995). Similar $a_{\mathrm{w}}$ conditions are tolerated by some xerophilic Penicillium species as $P$. chrysogenum growing above $0.78-0.81$ 240 (Hocking and Pitt, 1979; Sautour et al., 2001b) or P. roqueforti growing from 0.82 (Gock et al., 241 2003). The minimal $a_{\mathrm{w}}$ for growth obtained in our study was lower than results obtained from $P$. hordei, P.aurantiogriseum (Marin et al., 1998) and P. olsonii (Lopez-Diaz et al., 2002). Several other Penicillium species showed minimal $a_{\mathrm{w}}$ around 0.90 as $P$. expansum (Lahlali et al., 2005), $P$. verrucosum (Cairns-Fuller et al., 2005) or P. italicum and P. digitatum (Lahlali et al., 2006). 
The estimated optimal $a_{\mathrm{w}}$ condition was 0.98 which is in accordance with literature data on

this species, reporting also the same value (Sinigaglia et al., 1998). Most Penicillium species also showed similar response to medium $a_{\mathrm{w}}$ and optimal conditions around 0.97-0.98 (Hocking and Pitt, 1979). For example, the optimal $a_{\mathrm{w}}$ for growth was estimated to 0.98 for $P$. chrysogenum using the same CMI than that described by eq (2) in this study (Sautour et al., 2001a).

\subsection{Effect of pH}

Radial growth rate was almost constant in the $\mathrm{pH}$ range 2.0-7.0 (Fig. 3). Experimental data were fitted by the model eq (3) rather satisfactorily, as suggested by the low RMSE value, 0.089

(Table 2). The optimal and the maximal $\mathrm{pH}$ values were 5.5 and 11.2 respectively but the minimal $\mathrm{pH}$ was estimated in the negative range at -2.1. Application of another model (Zwietering et al., 1992), gave with even a higher RMSE, aberrant minimal $\mathrm{pH}$ when applied to the same data (results not shown).

These results obtained showed the difficulty to model the growth response of this strain under very acidic conditions. Future studies should be directed to find a convenient model that fits correctly the $\mathrm{pH}$ growth response of this filamentous fungus. Nevertheless, the experimental data obtained gave some precious information as no fungal growth was observed at $\mathrm{pH} 0.5$ which indicate that the minimal $\mathrm{pH}$ conditions seemed to be between 0.5 and 1.0. It differs from previous description of this species reporting a minimal pH value of 2.0 (Sinigaglia et al., 1998).

From the modeling of the $\mathrm{pH}$ response, the optimal $\mathrm{pH}$ condition of 5.5 and the large tolerance observed for this filamentous fungus towards a large range of $\mathrm{pH}$ conditions, were in accordance with literature describing optimal growth rate of many filamentous fungi around $\mathrm{pH} 5.0$ 269 (Pitt and Hocking, 1997) and in the pH range 3.0 to 8.0 (Wheeler et al., 1991). As reported in 
acidic ones. The $\mathrm{pH}$ response observed for this strain could be compared with other $\mathrm{pH}$ studies on several Penicillium species conducted in solid medium (Wheeler et al., 1991). From these results, $P$. citreonigrum seemed to present a similar response than $P$. glabrum and its optimum was defined at $\mathrm{pH}$ 4.4-6.3. The results obtained in our study were also similar to those observed for $P$. jensenii (Sacks et al., 1986) as this filamentous fungi seemed not very sensitive to $\mathrm{pH}$ range from 3.5 to 7.1 but showed an important fungal growth decrease just below at $\mathrm{pH}$ 3.3. P. roqueforti also showed a large tolerance to several $\mathrm{pH}$ values tested from 4.5 to 7.5 (Gock et al., 2003). In a large range of values, the medium $\mathrm{pH}$ seems to have a very low influence on the growth of this fungus as reported also for several Penicillium species between $\mathrm{pH}$ 4.0-10.0 (Thompson et al., 1993). The tolerance observed here for $P$. glabrum towards a large acid $\mathrm{pH}$ range may explain the presence of this species on a large variety of food products of different $\mathrm{pH}$. The $\mathrm{pH}$ sensibility increase in the alkaline range until the estimated maximal $\mathrm{pH}$ value of 11.18. This value seemed coherent with the results previously obtained on different Penicillium species (Wheeler et al., 1991).

Considering the good fit of the temperature and $a_{\mathrm{w}}$ models (RMSE of 0.077 and 0.078 respectively) and the estimated cardinal values, the method of CMI developed by Rosso et al., seemed well adapted to analyse the effect of both factors on the growth of this strain of P. glabrum. The robustness of the approach of Rosso et al. of has been reported in a study on the effects of temperature and $a_{\mathrm{w}}$ on Aspergillus carbonarius growth (Tassou et al., 2007). Analysis of the results obtained with other predictive mycology methods, showed that Rosso et al. approach was the most adapted to model the growth of this filamentous fungus in different conditions. This method has been successfully used, for example, in P. chrysogenum, Aspergillus flavus, A. parasiticus, A. oryzae to model the effect of $a_{\mathrm{w}}$ on fungal growth (Rosso and Robinson, 2001; Sautour et al., 2001a). This method has also the advantage to define fungal growth rate $(\mu)$, by 4 parameters with concrete physiological meaning: optimal growth $\left(\mu_{\mathrm{opt}}\right)$ and minimal, optimal and maximal conditions for each factor tested. Thus application and fitting of these models allowed to calculate 
these parameters for each factor tested. For this reason, the use of CMI method has been well

298 adapted to provide physiological characteristics of this strain of P. glabrum for temperature and $a_{\mathrm{w}}$.

299 Nevertheless some difficulties were shown to fit the experimental data with the CMI in very acidic 300 conditions. Cardinal models are versatile tools that can adapt to the different shapes of the curves $\mu$ 301 vs temperature and $\mu$ vs $a_{\mathrm{w}}$. There are no reason that could prevent the CMI from fitting data $\mathrm{pH} v s$ $302 \mathrm{pH}$ with a good accuracy. The lack of fit that was demonstrated under acidic $\mathrm{pH}$ may be due to no 303 data were available between $\mathrm{pH} 0.5$ and 1, but this should be verified.

The different results obtained in this study provide useful background to improve characterisation of the strain of P. glabrum isolated from PET bottled aromatised mineral water. The microbiological quality of bottled mineral water is of great interest but has not been very largely investigated. In addition to indigenous bacteria that do not induce any risk to public heath, mineral water may sometimes contain contaminants as bacteria or filamentous fungi. Some authors 310 described that the fungal foreign bodies visible in the mineral water samples, were made up of 311 pellets with a diameter of 3 to $20 \mathrm{~mm}$ (Fujikawa et al., 1997). The most frequent fungal genera 312 isolated from mineral water were Penicillium followed by Cladosporium, Trichoderma, 313 Aspergillus, Alternaria and Acremonium (Fujikawa et al., 1997; Liceaga-Gesualdo et al., 2001; 314 Hageskal et al., 2006). Among the genus Penicillium, P. citrinum and P. glabrum were the 2 most 315 isolated species (Cabral and Fernandez Pinto, 2002). Although filamentous fungi in water usually 316 do not generate public health problems, nevertheless some of the fungi isolated from bottled 317 mineral water as Alternaria alternata and P. citrinum have some toxigenic potential which could 318 determine some health risk (Cabral and Fernandez Pinto, 2002). The contamination of these products may be explained by microbial presence from the surrounding environment when filling and capping bottles of mineral water (Fujikawa et al., 1997).

321 This last hypothesis was supplied by the fact that many filamentous fungi as some Penicillium species disperse a large number of spores in the environment. 

very low nutritional requirements as it can develop in visible pellets in such a poor nutritive environment with slight carbohydrate concentrations, various salts and limited oxygen concentration as only a small fraction of air is enclosed in tight sealed bottles. In literature, it was also shown that sometimes, fungal contaminants could use as nutriments, organic compounds releases during storage, from PET (Criado et al., 2005), a beverage bottling material used for conditioning a large variety of commercialised water as the one which is studied here. This aromatised bottled mineral water presented a very high $a_{\mathrm{w}}$, a $\mathrm{pH}$ at 7.0 and the storage of this product was often made at room temperature (around $18-25{ }^{\circ} \mathrm{C}$ ). The characteristics of this aromatised mineral water may be favourable for the growth of this strain of $P$. glabrum by extrapolating its physiological requirements obtained in solid medium. Several authors have 334 previously reported the presence of this species in commercialised water (Cabral and Fernandez 335 Pinto, 2002; Ancasi et al., 2006). The contamination of this product by this filamentous fungus was also explained by its ubiquitous presence in the environment and its large conidiation in the atmosphere. Moreover, the physiological characteristics of this strain of $P$. glabrum seemed to present important similarities with the temperature, $a_{\mathrm{w}}$ and $\mathrm{pH}$ requirements of another frequent fungal contaminant of water products such as P. citrinum (Hocking and Pitt, 1979; Gonzalez et al., 1988; Montani et al., 1988; Wheeler et al., 1991; Comerio et al., 1998).

Precise characterisation of growth conditions of this strain of $P$. glabrum has an evident interest to understand its contamination abilities in food manufacturing industry. The influence of temperature, $a_{\mathrm{w}}$ and $\mathrm{pH}$ on fungal growth could be taken into account to maintain good conditions on stored product. Nevertheless these results should be considered carefully as fungal 346 contamination of different products could also concern several other species than P. glabrum and may interact in a competitive or associative way. 


\section{Acknowledgements}

This entire work was realised with the financial support of the Brittany region.

\section{References}

Ancasi, E.G., Carrillo, L., Benitez Ahrendts, M.R., 2006. Moulds and yeasts in bottled water and soft drinks. Rev. Argent Microbiol. 38, 93-96.

Baranyi, J., Roberts, T.A., McClure, P., 1993. A non-autonomous differential equation to model bacterial growth. Food Microbiol 10, 43-59.

Buchanan, R.L., 1993. Predictive food microbiology. Trends Food Sci Tech 4, 6-11.

Cabral, D., Fernandez Pinto, V.E., 2002. Fungal spoilage of bottled mineral water. Int. J. Food Microbiol. 72, 73-76.

Cairns-Fuller, V., Aldred, D., Magan, N., 2005. Water, temperature and gas composition interactions affect growth and ochratoxin A production by isolates of Penicillium verrucosum on wheat grain. J. Appl. Microbiol. 99, 1215-1221.

Comerio, R., Fernandez, P., V, Vaamonde, G., 1998. Influence of water activity on Penicillium citrinum growth and kinetics of citrinin accumulation in wheat. Int. J. Food Microbiol. 42, 219-223.

Criado, M.V., Fernandez, P., V, Badessari, A., Cabral, D., 2005. Conditions that regulate the growth of moulds inoculated into bottled mineral water. Int. J Food Microbiol. 99, 343-349.

Dantigny, P., Bensoussan, M., 2008. The logarithmic transformation should be avoided for stabilising the variance of mould growth rate. Int J Food Microbiol 121, 225-228.

Dantigny, P., Guilmart, A., Bensoussan, M., 2005. Basis of predictive mycology. Int. J. Food Microbiol. 100, 187-196.

Davey, K.R., 1989. A predictive model for combined temperature and water activity on microbial growth during the growth phase. J Appl Bacteriol. 67, 483-488.

Fujikawa, H., Wauke, T., Kusunoki, J., Takahashi, Y., Ohta, K., Itoh, T., 1997. Contamination of microbial foreign bodies in bottled mineral water in Tokyo, Japan. J Appl Microbiol 82, 287291.

Gibson, A.M., Baranyi, J., Pitt, J.I., Eyles, M.J., Roberts, T.A., 1994. Predicting fungal growth: the effect of water activity on Aspergillus flavus and related species. Int J Food Microbiol 23, 419-431.

Gibson, A.M., Hocking, A.D., 1997. Advances in the predictive modelling of fungal growth in food. Trends Food Sci Tech 353-358.

Gock, M.A., Hocking, A.D., Pitt, J.I., Poulos, P.G., 2003. Influence of temperature, water activity 
and $\mathrm{pH}$ on growth of some xerophilic fungi. Int. J. Food Microbiol. 81, 11-19.

Gonzalez, H.H., Resnik, S.L., Vaamonde, G., 1988. Influence of temperature on growth rate and lag phase of fungi isolated from Argentine corn. Int. J. Food Microbiol. 6, 179-183.

Hageskal, G., Knutsen, A.K., Gaustad, P., de Hoog, G.S., Skaar, I., 2006. Diversity and significance of mold species in Norwegian drinking water. Appl Environ. Microbiol 72, 7586-7593.

Hocking, A.D., Faedo, M., 1992. Fungi causing thread mould spoilage of vacuum packaged Cheddar cheese during maturation. Int. J. Food Microbiol. 16, 123-130.

Hocking, A.D., Pitt, J.I., 1979. Water relations of some Penicillium species at 25 deg C. T Brit mycol Soc 73, 141-145.

Kurata, H., Sakabe, F., Udagawa, S., Ichinoe, M., Suzuki, M., 1968. [A mycological examination for the presence of mycotoxin-producers on the 1954-1967's stored rice grains]. Eisei Shikenjo Hokoku 86, 183-188.

Lahlali, R., Serrhini, M.N., Friel, D., Jijakli, M.H., 2006. In vitro effects of water activity, temperature and solutes on the growth rate of $P$. italicum Wehmer and $P$. digitatum Sacc. J. Appl. Microbiol. 101, 628-636.

Lahlali, R., Serrhini, M.N., Jijakli, M.H., 2005. Studying and modelling the combined effect of temperature and water activity on the growth rate of P. expansum. Int. J. Food Microbiol. 103, $315-322$.

Lerici, C.R., Nicoli, M.C., Manzocco, L., 1996. Influenza dell'attività dell'acqua sulla tensione di vapore dell'etanolo in sistemi modello alimentar. Industrie Alimentari 35, 13-17.

Liceaga-Gesualdo, A., Li-Chan, E.C.Y., Skura, B.J., 2001. Antimicrobial effect of lactoferrin digest on spores of a Penicillium sp. isolated from bottled water. Food Res Int 34, 501-506.

Lopez-Diaz, T.M., Gonzalez, C.J., Moreno, B., Otero, A., 2002. Effect of temperature, water activity, $\mathrm{pH}$ and some antimicrobials on the growth of Penicillium olsonii isolated from the surface of Spanish fermented meat sausage. Food Microbiol 19, 1-7.

Marin, S., Sanchis, V., Saenz, R., Ramos, A.J., Vinas, I., Magan, N., 1998. Ecological determinants for germination and growth of some Aspergillus and Penicillium spp. from maize grain. J. Appl. Microbiol. 84, 25-36.

Miles, D.W., Ross, T., Olley, J., McMeekin, T.A., 1997. Development and evaluation of a predictive model for the effect of temperature and water activity on the growth rate of Vibrio parahaemolyticus. Int J Food Microbiol 38, 133-142.

Mislivec, P.B., Tuite, J., 1970. Species of Penicillium occurring in freshly-harvested and in stored dent corn kernels. Mycologia. 62, 67-74.

Montani, M., Vaamonde, G., Resnik, S.L., Buera, P., 1988. Temperature influence on Penicillium citrinum thom growth and citrinin accumulation kinetics. Int. J. Food Microbiol. 7, 115-122.

Northolt, M.D., Frisvad, J.C., Samson, R.A., 1995. Occurence of food-borne fungi and factors for growth. In: Samson, R.A., Hoekstra, E.S., Frisvad, J.C., Filtenborg, O. (Eds.), Introduction to food borne fungi Centraalbureau voor Schimmelcultures, Baarn, pp. 243-250. 
Northolt, M.D., van Egmond, H.P., Soentoro, P., Deijll, E., 1980. Fungal growth and the presence of sterigmatocystin in hard cheese. J. Assoc. Off Anal. Chem. 63, 115-119.

Nunez, F., Diaz, M.C., Rodriguez, M., Aranda, E., Martin, A., Asensio, M.A., 2000. Effects of substrate, water activity, and temperature on growth and verrucosidin production by Penicillium polonicum isolated from dry-cured ham. J. Food Prot. 63, 231-236.

Overy, D.P., Seifert, K.A., Savard, M.A., Frisvad, J.C., 2003. Spoilage fungi and their mycotoxins in commercially marketed chestnuts. Int J Food Microbiol 69-77.

Pitt, J.I., 1988. A laboratory guide to commun Penicillium species, Second edition. Food Science Australia.

Pitt, J.I., Hocking, A.D., 1997. Fungi and food spoilage, Second edition. Blackie academic and professional.

Plaza, P., Usall, J., Teixido, N., Vinas, I., 2003. Effect of water activity and temperature on germination and growth of Penicillium digitatum, P. italicum and Geotrichum candidum. J. Appl. Microbiol. 94, 549-554.

Ratkowsky, D.A., 2004. Model fitting and uncertainty. In: McKellar, R.C., Lu, X. (Eds.), Modeling microbial responses in food CRC Press, Boca Raton, Florida, USA, pp. 151-196.

Ratkowsky, D.A., Lowry, R.K., McMeekin, T.A., Stokes, A.N., Chandler, R.E., 1983. Model for bacterial culture growth rate throughout the entire biokinetic temperature range. J Bacteriol. $154,1222-1226$.

Rosso, L., Lobry, J.R., Bajard, S., Flandrois, J.P., 1995. Convenient Model To Describe the Combined Effects of Temperature and pH on Microbial Growth. Appl Environ. Microbiol 61, 610-616.

Rosso, L., Lobry, J.R., Flandrois, J.P., 1993. An unexpected correlation between cardinal temperatures of microbial growth highlighted by a new model. J Theor. Biol. 162, 447-463.

Rosso, L., Robinson, T.P., 2001. A cardinal model to describe the effect of water activity on the growth of moulds. Int J Food Microbiol 63, 265-273.

Sacks, L.E., King, A.D., Jr., Schade, J.E., 1986. A note of $\mathrm{pH}$ gradient plates for fungal growth studies. J. Appl. Bacteriol. 61, 235-238.

Samson, R.A., Hoekstra, E.S., Frisvad, J.C., Filtenborg, O., 2004. Introduction to food and airborne fungi, seventh edition. Centraalbureau voor Schimmelcultures (CBS), Utrecht, Netherlands.

Sautour, M., Dantigny, P., Divies, C., Bensoussan, M., 2001a. A temperature-type model for describing the relationship between fungal growth and water activity. Int J Food Microbiol 67, 63-9.

Sautour, M., Rouget, A., Dantigny, P., Divies, C., Bensoussan, M., 2001b. Prediction of conidial germination of Penicillium chrysogenum as influenced by temperature, water activity and $\mathrm{pH}$. Lett Appl Microbiol 32, 131-4.

Sinigaglia, M., Corbo, M.R., Ciccarone, C., 1998. Influence of temperature, pH and water activity on "in vitro" inhibition of Penicillium glabrum (Wehmer) Westling by yeasts. Microbiol. Res. $153,137-143$. 
Tassou, C.C., Panagou, E.Z., Natskoulis, P., Magan, N., 2007. Modelling the effect of temperature and water activity on the growth of two ochratoxigenic strains of Aspergillus carbonarius from Greek wine grapes. J Appl Microbiol 103, 2267-2276.

464 Thompson, D.P., Metevia, L., Vessel, T., 1993. Influence of $\mathrm{pH}$ alone and in combination with 465 phenolic antioxidants on growth and germination of mycotoxigenic species of fusarium and 466 penicillium. J Food prot 56, 134-138.

Udagawa, S.I., Kobatake, M., Kurata, H., 1977. [Re--estimation of preservation effectiveness of potassium sorbate (food additive) in jams and marmalade (author's transl)]. Eisei Shikenjo Hokoku 88-92.

Wheeler, K.A., Hurdman, B.F., Pitt, J.I., 1991. Influence of $\mathrm{pH}$ on the growth of some toxigenic species of Aspergillus, Penicillium and Fusarium. Int. J. Food Microbiol. 12, 141-149.

Zwietering, M.H., Wijtzes, T., de Witt, J.C., van't Riet, K., 1992. A decision support system for prediction of the microbial spoilage in foods. J Food prot 55, 973-979. 